\title{
Hepatocyte RXR alpha deletion in mice leads to inhibition of angiogenesis
}

\author{
Urszula Razny · Lukasz Wator • Anna Polus • \\ Yu-Jui Yvonne Wan · Grzegorz Dyduch • \\ Romana Tomaszewska · Aldona Dembinska-Kiec
}

Received: 23 January 2009/Accepted: 26 January 2009/Published online: 18 February 2009

(C) Springer-Verlag 2009

\begin{abstract}
To investigate the effect of RXR $\alpha$ deficiency in liver on angiogenesis, hepatocyte $\operatorname{RXR} \alpha$-deficient and control wild-type mice were fed either standard or high-fat $\operatorname{diet}(\mathrm{HF})$ for 7 weeks. In the 6th week of feeding, Matrigel model of in vivo angiogenesis was applied. Matrigel plug infiltrating cells were then used for visualization of vessels (CD31 staining) as well as for gene expression analysis. HF diet appeared to decrease angiogenesis in $\mathrm{hRXR} \alpha$-deficient mice. Genes related to angiogenesis (Nos3, Kdr) were down-regulated, whereas genes connected with adipogenesis (Cebpb, Srebf1), apoptosis (Gzmb, Bcl2) and proinflammatory pathway $(N f \kappa B, T n f \alpha)$ were up-regulated by $\mathrm{HF}$ diet in $\mathrm{hRXR} \alpha$-deficient mice in the microarray study. Our results suggest that impaired fatty acid metabolism in liver ( $\mathrm{hRXR} \alpha$-deficient mice) leads to impaired angiogenesis due to lipotoxicity and promotion of adipogenesis.
\end{abstract}

Keywords Adipogenesis - Angiogenesis - FFA · Retinoid X receptor

U. Razny $(\bowtie) \cdot$ L. Wator · A. Polus · A. Dembinska-Kiec Department of Clinical Biochemistry, Jagiellonian University Medical College, Kopernika 15a Street, 31-501 Cracow, Poland e-mail: urazny@cm-uj.krakow.pl

G. Dyduch $\cdot$ R. Tomaszewska

Department of Pathomorphology, Jagiellonian University

Medical College, Grzegorzecka 16 Street, 31-531 Cracow,

Poland

Y.-J. Y. Wan

Department of Pharmacology, Toxicology and Therapeutics, University of Kansas Medical Center, 3901 Rainbow Boulevard, Kansas City, KS 66160, USA

\section{Introduction}

Angiogenesis, the process of the new blood vessels formation, is a combined result of tissue growth and tissue remodeling, which also includes adipose tissue [2,9]. Several factors such as vascular endothelial growth factor (VEGF), basic fibroblast growth factor (bFGF), nitric oxide (NO) as well as insulin-like growth factor 1 (IGF-1), insulin, adipokines (leptin, adiponectin) and several others play important roles in the angiogenic response [8]. The substances listed above regulate the most important steps in angiogenesis like proliferation, migration, homing and differentiation of the vascular wall progenitor cells. Our previous studies indicated that beta-carotene exerted proangiogenic activity by stimulating endothelial cell migration and homing [4]. The retinoic acid derived from beta-carotene cooperates with free fatty acids (FFA) and its metabolites in lipid metabolism by regulating heterodimer PPAR/RXR activation. Thus, targeted deletion of $\mathrm{RXR} \alpha$ gene in hepatocytes leads to dysfunction of enzymes participating in cholesterol, FFA, bile acids, steroids and xenobiotics metabolism [7, 15]. Mice with hepatocytes RXR $\alpha$ deficiency fed a high-fat diet displayed elevated serum triglycerides, increased apo CIII mRNA levels, and higher cholesterol and leptin concentrations in serum [10-12]. The present study was undertaken to define the effect of dyslipidemia induced by RXR alpha deficiency in the liver on angiogenic response in vivo, in mice model.

\section{Methods}

Mice

Mice deficient in hepatocyte $\mathrm{RXR} \alpha$-gene were described elsewhere [11]. The hepatocyte $\operatorname{RXR} \alpha$ deletion was 
introduced in the mixed genetic background of C57/B16, 129/svEvTac and DBA-2 mice [11]. The animals used in the experiments were kindly supplied by Dr. Yu-Jui Yvonne Wan (University of Kansas Medical Center).

Mice were age-matched (males), housed in cages at $22^{\circ} \mathrm{C}$ with 12/12-h light/dark cycle with free access to food and water. The animals were fed either standard lab chow diet containing $3 \%$ fat or high-fat (HF) diet (high saturated fat diet, coconut oil based, 39en\% fat) (MP Biomedical Research, USA) for 7 weeks. The study protocol was approved by the local University Ethical Committee (JUMC).

\section{Angiogenesis in vivo}

In the 6th week of standard and HF diet, the mice were subcutaneously dorsally injected with Matrigel (Becton Dickinson; $2 \times 500 \mu \mathrm{l})$ that contained bFGF $[25 \mathrm{nM}]$ for 6 days. Matrigel plugs were then removed from the mice. Matrigel infiltrating cells were analyzed for specific gene expression and they were immunohistochemically stained with rat anti-mouse CD31 antibodies specific for platelet/ endothelial cell adhesion molecule (anti-PECAM1, Becton Dickinson) [13]. The number of newly formed capillaries (with and without lumen) was counted using a "hot spot" method described previously [14]. The images were analyzed in five fields in three slides taken from different parts of each plug.

\section{Microarray analysis}

The differences in angiogenic gene expression in Matrigel infiltrating cells were monitored by means of a microarray analysis (Affymetrix 430A_2 GeneChips), of which results were evaluated with Affymetrix microarray analysis suit. The genes selected for further analysis included the ones with significant differences in signal intensity $(P<0.05)$ and relative change in their expression greater than 1.4-fold.

\section{Statistics}

All results were presented as mean values \pm standard deviation (SD). The $t$ Student's test was applied to determine the significance between analyzed factors; $P$ values lower than $0.05 \quad(P<0.05)$ were considered to be significant.

\section{Results}

Hepatocyte RXR $\alpha$-deficient mice and their wild-type counterparts were fed regular and HF diet for 6 weeks in order to elucidate the role of hepatocyte RXR $\alpha$ in angiogenesis under different lipemic conditions. The animals were injected with Matrigel (BD), which was later removed and analyzed for angiogenic response and gene expression in the infiltrated cells. The $\mathrm{hRXR} \alpha$-deficient mice demonstrated a tendency to weaker angiogenic response compared to the wild-type mice when supplied with HF diet (Fig. 1). In addition, high-fat (HF) diet induced downregulation of a number of angiogenic genes in hepatocyte $\operatorname{RXR} \alpha$-deficient mice as demonstrated by Affymetrix microarray analysis of gene expression in the cells infiltrating Matrigel plugs (Table 1). Gene expression of such growth factor receptors as $K d r$ (vascular endothelial growth factor receptor-2) or Pdgfrb (platelet-derived growth factor receptor beta) that induce proliferation and migration of endothelial cells was significantly reduced. Activity of Nos3 gene (endothelial nitric oxide synthase) that regulates vasodilatation, endothelial cell protection and angiogenesis [1] was also inhibited.

The high-fat diet resulted in up-regulation of proapoptotic genes in the Matrigel-infiltrating cells derived from $h R X R \alpha$-deficient mice. Expression of the genes encoding activators of caspase 3 [Prfl (perforin 1), Gzmb (granzyme B)], pro-apoptotic Bcl2L11 (Bcl2 interacting mediator of cell death), $\mathrm{NF} \kappa \mathrm{B}$ pathway [Nfkbie (nuclear factor of kappa light polypeptide gene enhancer in B-cells inhibitor), $N f k b l$ (nuclear factor of kappa light polypeptide gene enhancer in B-cells 1)], TNF $\alpha$ receptors [Tnfrsf 21 (tumor necrosis factor receptor superfamily, member 21),

\section{WT $\otimes$ hRXRako}

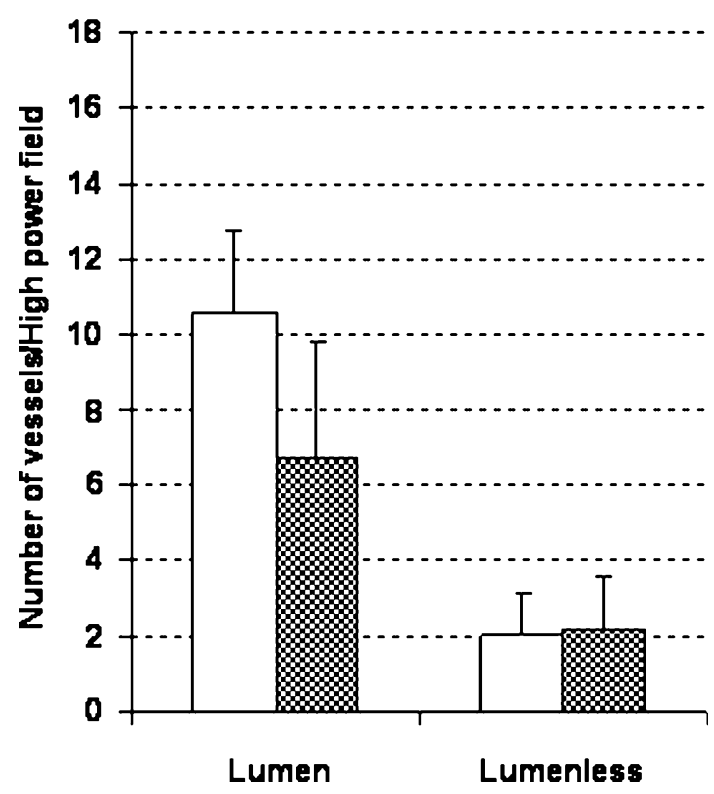

Fig. 1 Number of vessels with lumen and without lumen in Matrigel plug of wild-type and hepatocyte RXR $\alpha$-deficient (hRXRa ko) mice fed with a high-fat diet. Values are expressed as mean $\pm \operatorname{SD}(n=5)$ 
Table 1 Comparison of microarray changes in relative gene expression (between Matrigel plug cells from mice fed with a standard diet (ST) and matrigel plug cells from mice fed with a high-fat diet (HF)) in RXR $\alpha$-deficient mice (hRXRa ko) and WT mice

\begin{tabular}{|c|c|c|}
\hline Gene symbol & $\begin{array}{l}\text { WT } \\
\text { HF vs ST }\end{array}$ & $\begin{array}{l}\text { hRXRa ko } \\
\text { HF vs ST }\end{array}$ \\
\hline \multicolumn{3}{|l|}{ Angiogenesis } \\
\hline $\mathrm{Kdr}$ & $\mathrm{nc}$ & $-1.87^{\mathrm{a}}$ \\
\hline Pdgfrb & $\mathrm{nc}$ & $-1.52^{\mathrm{a}}$ \\
\hline Nos3 & $\mathrm{nc}$ & $-2.64^{\mathrm{a}}$ \\
\hline \multicolumn{3}{|l|}{ Apoptosis } \\
\hline Prf1 & $-4.29^{\mathrm{a}}$ & $2.14^{\mathrm{b}}$ \\
\hline Gzmb & $-5.66^{\mathrm{a}}$ & $9.85^{\mathrm{b}}$ \\
\hline $\mathrm{Bc} 2111$ & $-1.87^{\mathrm{a}}$ & $1.41^{\mathrm{b}}$ \\
\hline Nfkbie & $-2.14^{\mathrm{a}}$ & $4^{\mathrm{b}}$ \\
\hline Nfkb1 & $-1.32^{\mathrm{a}}$ & $1.52^{\mathrm{b}}$ \\
\hline Nfkbia & $-1.52^{\mathrm{a}}$ & $1.32^{\mathrm{b}}$ \\
\hline Tnfrsf21 & $-1.52^{\mathrm{a}}$ & $2^{\mathrm{b}}$ \\
\hline Tnfrsf1b & $-2.14^{\mathrm{a}}$ & $1.87^{\mathrm{b}}$ \\
\hline Casp3 & $-1.62^{\mathrm{a}}$ & $\mathrm{nc}$ \\
\hline Casp6 & $-1.74^{\mathrm{a}}$ & $\mathrm{nc}$ \\
\hline Birc5 & $\mathrm{nc}$ & $-1.41^{\mathrm{a}}$ \\
\hline Birc4 & $\mathrm{nc}$ & $-1.52^{\mathrm{a}}$ \\
\hline \multicolumn{3}{|l|}{ Adipogenesis } \\
\hline Cebpb & $-3.48^{\mathrm{a}}$ & $1.74^{\mathrm{b}}$ \\
\hline Srebf1 & $\mathrm{nc}$ & $1.74^{\mathrm{b}}$ \\
\hline Adipoq & $3.73^{\mathrm{b}}$ & $-6.96^{\mathrm{a}}$ \\
\hline Retn & $\mathrm{nc}$ & $-6.06^{\mathrm{a}}$ \\
\hline Adn & $7.46^{\mathrm{b}}$ & $-13^{\mathrm{a}}$ \\
\hline Fabp4 & $1.62^{\mathrm{b}}$ & $-4.92^{\mathrm{a}}$ \\
\hline Lpl & $3.03^{\mathrm{b}}$ & $\mathrm{nc}$ \\
\hline
\end{tabular}

$n c$ no change

${ }^{a}$ Down-regulated genes

b Up-regulated genes

Tnfrsflb (tumor necrosis factor receptor superfamily, member 1b)] was increased, while some inhibitors of apoptosis [Birc5 (baculoviral IAP repeat-containing 5), Birc4 (baculoviral IAP repeat-containing 4)] were downregulated. In contrast, high-fat diet affected the expression of the above pro-apoptotic genes in the Matrigel-populating cells from the wild-type (WT) mice in the opposite way to the mutant cells. Expression of the genes encoding caspases (Casp3, Casp6), TNF receptors (Tnfrsf21, Tnfrsflb) NF $\kappa \mathrm{B}$ pathway (Nfkbie, $N f k b 1$ ), Bcl211, perforin 1 (Prfl) and granzyme B (Gzmb) was uniformly decreased by $1.32(N f k b l b)$ to $5.66(G z m b)$-fold (Table 1$)$.

$\mathrm{HF}$ diet also promoted expression of transcription factors important in the early steps of adipogenesis in the Matrigel-infiltrating cells from $\mathrm{hRXR} \alpha$-deficient mice. Genes encoding transcription factors recognized as essential for adipogenesis [5], such as Cebpb (CCAAT/ enhancer binding protein $\beta$ ) or Srebfl (sterol regulatory element binding factor 1), were up-regulated, whereas markers of differentiated adipocytes that included Adipoq (adiponectin), Retn (resistin), Adn (adipsin) and Fabp4 (fatty acid binding protein 4) were down-regulated. Surprisingly, in WT control mice, HF diet resulted in decrease of gene expression of $C e b p b$ that regulates pre-adipocyte differentiation, while genes associated with adipocyte differentiation, Adipoq, Adn, Fabp4, and Lpl (lipoprotein lipase), were up-regulated (Table 1).

\section{Discussion}

We demonstrated that mice with hepatocyte RXR alpha deficiency manifest tendency to decreased angiogenic response in the Matrigel model. The number of the blood vessels with lumen was smaller in the Matrigel plugs removed from the mutant mice compared to the wild-type control ones under a high-fat diet. This histopathological observation was confirmed by the gene expression analysis of the cells harvested from the Matrigel plug. Genes critical for angiogenesis, such as $K d r$, the receptor for VEGF, and Nos3, endothelial constitutive nitric oxide synthase important for vascular network formation [1], were clearly down-regulated. Our notion that new vessel formation in the Matrigel plugs from $\operatorname{hRXR} \alpha$-deficient animals was reduced due to inhibition of angiogenic response was also supported by decreased gene expression of integrins, gap junction proteins and matrix remodeling enzymes such as metalloproteinases (data not shown).

We propose that impaired angiogenesis observed in $\mathrm{hRXR} \alpha$-deficient mice is related on one hand to lipotoxicity of FFA, and on the other to activation of adipogenesis. Deficiency of $\operatorname{RXR} \alpha$ in liver could lead to increased level of circulating FFA in the blood, which could result in lipotoxicity, endothelial dysfunction and apoptosis of peripheral tissues [3]. It was shown that excess of FFA leads to lipotoxicity of endothelium by increased de novo synthesis of diacylglycerol and activation of protein kinase $\mathrm{C}$ (PKC) that initiates a cascade of events leading to stimulation of endothelial superoxide production, inhibition of NOS3 activity and activation of nuclear factor $\mathrm{NF}-\kappa \mathrm{B}$ [6]. In microarray study, we observed that HF diet in the matrigel plug of $\mathrm{hRXR} \alpha$-deficient mice resulted in activation of PKC gene expression (data not shown), inhibition of $N o s 3$ and up-regulation of proinflammatory pathways: $\mathrm{NF}-\kappa \mathrm{B}$ and $\mathrm{TNF} \alpha$ receptors. Our observation that pro-apoptotic genes are up-regulated under HF diet in the absence of hepatocyte $\mathrm{RXR} \alpha$ reinforces the hypothesis that FFA-induced lipotoxicity is the cause of the impaired angiogenic response. Increased caspase activity promoted 
by $\operatorname{Prfl}, G z m b$, up-regulation of pro-apoptotic protein Bcl2L11 and inhibition of antiapoptotic genes (Birc4, Birc5) confirm the induction of apoptosis in the Matrigel infiltrating cells. On the contrary, in control WT mice, HF diet resulted in down-regulation of the expression of proapoptotic genes such as: caspases and their activators. Beside down-regulation of the listed proangiogenic factors, HF diet activated early modulators of adipocyte differentiation such as transcription factors: (Srebfl, Cebpb) in the cells from $\mathrm{hRXR} \alpha$-deficient mice.

In summary, the presented study demonstrates that HF diet leads to biochemical changes that result in impaired angiogenic response in the hepatocyte $\mathrm{RXR} \alpha$-deficient mice. The observed decline in the formation of new blood vessels is due to the parallel activation of the expression of proadipogenic and proapoptotic genes in the cells involved in angiogenesis.

Acknowledgments This study was supported by the Polish Committee of Science Grant No: PBZ-MIN-005/P04/2002/5, NuGO contract FP6-2004-506360, 2 P05A 142 30, National Institutes of Health grants CA53596, AA14147, and COBRE P20 RR021940, the Molecular Biology Core under COBRE as well as the Liver Center at KUMC. The author would like to thank Phd Anna Knapp for the kind help in the preparation of the paper.

Conflict of interest statement There is no conflict of interest.

\section{References}

1. Ahmad S, Hawett PW, Wang P, Al-Ani B, Cudmore M, Fujisawa T, Haigh JJ, le Noble F, Wang L, Mukhopadhyay D, Ahmed A (2006) Direct evidence for endothelial vascular endothelial growth factor receptor-1 function in nitric oxide-mediated angiogenesis. Circ Res 99:715-722

2. Cao Y (2007) Angiogenesis modulates adipogenesis and obesity. J Clin Invest 117:2362-2368

3. Chinen I, Shimabukuro M, Yamakawa K, Higa N, Matsuzaki T, Noguchi K, Ueda S, Sakanashi M, Takasu N (2007) Vascular lipotoxicity: endothelial dysfunction via fatty acid-induced reactive oxygen species overproduction in obese Zucker diabetic fatty rats. Endocrinology 148:160-165

4. Dembinska-Kiec A, Polus A, Kiec-Wilk B, Grzybowska J, Mikolajczyk M, Hartwich J, Razny U, Szumilas K, Banas A, Bodzioch M, Stachura J, Dyduch G, Laidler P, Zagajewski J, Langman T, Schmitz G (2005) Proangiogenic activity of beta-carotene is coupled with the activation of endothelial cell chemotaxis. Biochim Biophys Acta 1740:222-239

5. Fève B (2005) Adipogenesis: cellular and molecular aspect: best practice and research. Clin Endocrinol Metab 19:483-499

6. Inoguchi T, Li P, Umeda F, Yu HY, Kakimoto M, Imamura M (2000) High glucose level and free fatty acid stimulate reactive oxygen species production through protein kinase $\mathrm{C}$-dependent activation of $\mathrm{NAD}(\mathrm{P}) \mathrm{H}$ oxidase in cultured vascular cells. Diabetes 49:1939-1945

7. Kiec-Wilk B, Dembinska-Kiec A, Olszanecka A, Bodzioch M, Kawecka-Jaszcz K (2005) The selected pathophysiological aspects of PPARs activation. J Physiol Pharmacol 56:149-162

8. Papetti M, Herman IM (2002) Mechanisms of normal and tumor-derived angiogenesis. Am J Physiol Cell Physiol 282:947-970

9. Polverini PJ (2002) Angiogenesis in health and disease: insights into basic mechanisms and therapeutic opportunities. J Dent Educ 66:962-975

10. Wan YJ, An DJ, Cai Y, Repa JJ, Hung-Po Chen T, Flores M, Postic C, Magnuson MA, Chen J, Chien KR, French S, Mangelsdorf DJ, Sucov HM (2000) Hepatocyte-specific mutation establishes retinoid $\mathrm{X}$ receptor $\alpha$ as a heterodimeric integrator of multiple physiological processes in the liver. Mol Cell Biol 20:4436-4444

11. Wan YJ, Cai Y, Lungo W, Fu P, Locker J, French S, Sucov HM (2000) Peroxisome proliferator-activated receptor $\alpha$-mediated pathways are altered in hepatocyte-specific retinoid $\mathrm{X}$ receptor $\alpha$-deficient mice. J Biol Chem 275:28285-28290

12. Wan YJ, Han G, Cai Y, Dai T, Konishi T, Leng AS (2003) Hepatocyte retinoid $X$ receptor- $\alpha$-deficient mice have reduced food intake, increased body weight, and improved glucose tolerance. Endocrinology 144:605-611

13. Vucenik I, Passaniti A, Vitolo MI, Tantivejkul K, Eggleton P, Shasuddin AM (2004) Anti-angiogenic activity of inositol hexaphosphate (IP6). Carcinogenesis 11:2115-2123

14. West CML, Cooper RA, Loncaster JA, Wilks DP, Bromley M (2001) Tumor vascularity: a histological measure of angiogenesis and hypoxia. Cancer Res 61:2907-2910

15. Villarroya F, Iglesias R, Giralt M (2004) Retinoids and retinoid receptors in the control of energy balance: novel pharmacological strategies in obesity and diabetes. Curr Med Chem 11:795-805 